Research paper

\title{
Relationship between sedentary behavior and depression: A mediation analysis of influential factors across the lifespan among 42,469 people in low- and middle-income countries
}

\author{
Brendon Stubbs ${ }^{\mathrm{a}, \mathrm{b}, \mathrm{c}, *, 1}$, Davy Vancampfort ${ }^{\mathrm{d}, \mathrm{e}, 1}$, Joseph Firth $^{\mathrm{f}, \mathrm{g}}$, Felipe B. Schuch ${ }^{\mathrm{h}, \mathrm{i}, \mathrm{j}}$, \\ Mats Hallgren $^{\mathrm{k}}$, Lee Smith ${ }^{1}$, Benjamin Gardner ${ }^{\mathrm{m}}$, Kai.G. Kahl ${ }^{\mathrm{n}}$, Nicola Veronese ${ }^{\mathrm{o}}$, Marco Solmi ${ }^{\mathrm{p}, \mathrm{q}}$, \\ André F. Carvalho ${ }^{\mathrm{r}}$, Ai Koyanagi ${ }^{\mathrm{s}, \mathrm{t}}$
}

${ }^{\text {a }}$ Physiotherapy Department, South London and Maudsley NHS Foundation Trust, Denmark Hill, London SE5 8AZ, United Kingdom

${ }^{\mathrm{b}}$ Health Service and Population Research Department, Institute of Psychiatry, Psychology and Neuroscience, King's College London, De Crespigny Park, London Box SE5 $8 A F$, United Kingdom

${ }^{\mathrm{c}}$ Faculty of Health, Social Care and Education, Anglia Ruskin University, Chelmsford, United Kingdom

${ }^{\mathrm{d}}$ KU Leuven Department of Rehabilitation Sciences, Leuven, Belgium

e KU Leuven, University Psychiatric Center KU Leuven, Leuven-Kortenberg, Belgium

${ }^{\mathrm{f}}$ NICM, School of Health and Science, University of Western Sydney, Australia

${ }^{\mathrm{g}}$ Division of Psychology and Mental Health, Faculty of Biology, Medicine and Health, University of Manchester, United Kingdom

h Unilasalle, Canoas, Brazil

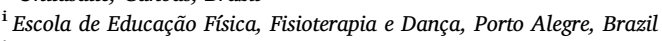

${ }^{\mathbf{j}}$ Department of Psychiatry, Universidade Federal do Rio Grande do Sul / Hospital de Clínicas de Porto Alegre, Porto Alegre, Brazil

${ }^{\mathbf{k}}$ Department of Public Health Sciences, Karolinska Institutet, Stockholm, Sweden

${ }^{1}$ The Cambridge Centre for Sport and Exercise Sciences, Department of Life Sciences, Anglia Ruskin University, Cambridge, United Kingdom

${ }^{\mathrm{m}}$ Department of Psychology, Institute of Psychiatry, Psychology and Neuroscience, King's College London, Addison House, Guy's Campus, London SE1 1UL, United

Kingdom

n Department of Psychiatry, Social Psychiatry and Psychotherapy, Hannover Medical School, Carl-Neuberg-Str. 1, 30625 Hannover, Germany

${ }^{\circ}$ National Research Council, Neuroscience Institute, Aging Branch, Padova, Italy

${ }^{\mathrm{P}}$ Department of Neurosciences, University of Padova, Padova, Italy

${ }^{\mathrm{q}}$ Local Health Unit 17 ULSS 17, Mental Health Department, Padova, Italy

${ }^{\mathbf{r}}$ Department of Clinical Medicine and Translational Psychiatry Research Group, Faculty of Medicine, Federal University of Ceará, Fortaleza, CE, Brazil

${ }^{\mathrm{s}}$ Research and Development Unit, Parc Sanitari Sant Joan de Déu, Universitat de Barcelona, Fundació Sant Joan de Déu, Dr. Antoni Pujadas, 42, Sant Boi de Llobregat, Barcelona 08830, Spain

${ }^{\mathrm{t}}$ Instituto de Salud Carlos III, Centro de Investigación Biomédica en Red de Salud Mental, CIBERSAM, Monforte de Lemos 3-5 Pabellón 11, Madrid 28029, Spain

\section{A R T I C L E I N F O}

\section{Keywords:}

Sedentary behavior

Sitting

Physical activity

Depression

Low- and middle-income countries

\section{A B S T R A C T}

Background: Sedentary behavior (SB) is associated with diabetes, cardiovascular disease and low mood. There is a paucity of multi-national research investigating SB and depression, particularly among low- and middle-income countries. This study investigated the association between SB and depression, and factors which influence this.

Methods: Cross-sectional data were analyzed from the World Health Organization's Study on Global Ageing and Adult Health. Depression was based on the Composite International Diagnostic Interview. The association between depression and SB (self-report) was estimated by multivariable linear and logistic regression analyses. Mediation analysis was used to identify influential factors.

Results: A total of 42,469 individuals (50.1\% female, mean 43.8 years) were included. People with depression spent 25.6 (95\%CI8.5-42.7) more daily minutes in SB than non-depressed participants. This discrepancy was most notable in adults aged $\geq 65 \mathrm{y}$ (35.6 min more in those with depression). Overall, adjusting for sociodemographics and country, depression was associated with a 1.94 (95\%CI1.31-2.85) times higher odds for high SB (i.e., $\geq 8 \mathrm{~h}$ /day). The largest proportion of the SB-depression relationship was explained by mobility limitations (49.9\%), followed by impairments in sleep/energy (43.4\%), pain/discomfort (31.1\%), anxiety (30.0\%), disability (25.6\%), cognition (16.1\%), and problems with vision $(11.0 \%)$. Other health behaviors (physical

\footnotetext{
* Corresponding author at: Physiotherapy Department, South London and Maudsley NHS Foundation Trust, Denmark Hill, London, United Kingdom.

E-mail address: brendon.stubbs@kcl.ac.uk (B. Stubbs).

${ }^{1}$ Joint first authors.
} 
activity, alcohol consumption, smoking), body mass index, and social cohesion did not influence the SB-depression relationship.

Conclusion: People with depression are at increased risk of engaging in high levels of SB. This first multi-national study offers potentially valuable insight for a number of hypotheses which may influence this relationship, although testing with longitudinal studies is needed.

\section{Introduction}

Depression is a leading cause of global years lived with disability (Whiteford et al., 2015). Whilst depression is associated with elevated mortality due to suicide (Hawton et al., 2013), cardio-metabolic diseases are the leading cause of premature death (Correll et al., 2017). It is known that people with depression have a double increased risk for diabetes and cardiovascular diseases compared to the general population (Vancampfort et al., 2015, 2016; Stubbs et al., 2017b, c, d).

There is established evidence that physical activity (PA) is good for health and confers comparable benefits to pharmacological interventions for preventing cardiovascular mortality (Naci and Ioannidis, 2013). People with established depression are known to engage in low levels of moderate-vigorous PA and are less likely than age-sex matched controls to meet recommended PA guidelines (Schuch et al., 2016a, b). Recent research has demonstrated that low levels of physical activity (PA) are consistently associated with an elevated risk for depression (Mammen and Faulkner, 2013; Stubbs et al., 2016b, c, d). Furthermore, engaging in structured physical activity ("exercise") has been demonstrated to be an effective treatment for depression (Schuch et al., 2016a, b).

There is also increasing evidence in the general population demonstrating that sedentary behavior (SB) is associated with a range of deleterious outcomes such as diabetes, cancer, cardiovascular disease and associated premature mortality (Biswas et al., 2015). SB refers to any waking behavior characterized by an energy expenditure $\leq 1.5$ metabolic equivalents (METs), while in a sitting, reclining or lying posture (Sedentary Behaviour Research, 2012; Tremblay et al., 2017). Much like depression, SB is highly prevalent and pervasive in societies across the world (Bennie et al., 2013; Ekelund et al., 2016a, 2016b; Loyen et al., 2016). Within the past five years, there has been growing interest in the potential relationship between SB and depression. A recent meta-analysis, almost exclusively among high-income countries, found that among 110,152 individuals, higher levels of SB were associated with depression (relative risk 1.31 (95\%CI 1.16-1.48)) (Zhai et al., 2015). Whilst recent advances in the literature have shone light on this neglected issue, a number of biases and gaps exist in the literature exploring the relationship between SB and depression to date. First, there is a paucity of multinational studies exploring the association between depression and SB. The current focus of micro-populations within specific countries may have limited utility beyond their immediate setting. Second, there is notably limited data on this association in low- and middle-income countries (LMICs), despite the increasing rates of non-communicable diseases and sedentary lifestyles (Christensen et al., 2009) in LMICs. Exploring associations between depression and SB in LMICs is also important given the high levels of depression (Guerra et al., 2016) and the low levels of knowledge regarding the risks associated with SB in LMICs (Pengpid et al., 2015), and compared with HICs, different occupational and socio-cultural structures, methods of transportation, and environmental factors (e.g., safety, climate) (Atkinson et al., 2016). The continuing dearth of studies from LMICs also highlights the gap between where research is conducted and where the largest public health impacts of physical inactivity (defined as not meeting recommended physical activity guidelines) occur (Sallis et al., 2016). Third, many studies investigating the association between SB and depression have relied upon screening tools such as the Patient Health Questionnaire (Adamson et al., 2016), which have limited sensitivity and specificity for identifying "true" depression (Mitchell et al., 2016). Finally, despite the association between depression and SB reported in previous high-income populations, a paucity of research has considered what variables might influence the relationship. Clearly, understanding the influential factors in this relationship, such as sociodemographic (e.g. age, sex, employment status), mental/physical health (e.g. physical comorbidities) and health behaviors (e.g. smoking, alcohol use, mobility), may prove useful for developing effective interventions in the future.

The current study used a large, multi-national sample and sought to investigate (1) the association between depression and SB across 6 LMICs; and (2) to investigate the factors that may explain the relation between depression and SB.

\section{Methods}

\subsection{The survey}

Data from the Study on Global Ageing and Adult Health (SAGE) survey was analyzed. The survey was conducted between 2007 and 2010 in China, Ghana, India, Mexico, Russia, and South Africa, which were all LMICs at the time of the survey according to the World Bank classification. Details of the survey methodology are provided elsewhere (Kowal et al., 2012). Briefly, in order to obtain nationally representative samples, a multi-stage clustered sampling design method was used. The sample consisted of adults aged $\geq 18$ years with oversampling of those aged $\geq 50$ years. Trained interviewers conducted face-to-face interviews using a standard questionnaire across countries to collect information. Standard translation procedures for the questionnaires were undertaken to ensure comparability between countries. Sampling weights were calculated to adjust for the population structure as reported by the United Nations Statistical Division. Ethical approval was obtained from the WHO Ethical Review Committee and local ethics research review boards. Written informed consent was obtained from all participants. The survey response rate ranged from $51 \%$ (Mexico) to 93\% (China). Full details of the sampling strategy are displayed in supplementary file 1 .

\subsection{Variables}

\subsubsection{Sedentary behavior (Outcome variable)}

In order to assess SB, participants were asked to state the total time they usually spent (expressed in minutes per day) sitting or reclining including at work, at home, getting to and from places, or with friends (e.g., sitting at a desk, sitting with friends, travelling in car, bus, train, reading, playing cards or watching television). This did not include time spent sleeping. The variable on SB was used in the analysis as a continuous variable (minutes per day) and also as a categorical $[<8$ or $\geq$ $8 \mathrm{~h}$ per day (high SB)] variable in line with recent publications (Vancampfort et al., 2017a, b). The eight-hour cut-off was chosen as previous research indicated that being sedentary for $\geq 8 \mathrm{~h} /$ day in the general population is associated with a higher risk for premature mortality (Ekelund et al., 2016a, b).

\subsubsection{Depression (Exposure variable)}

Questions based on the World Mental Health Survey version of the Composite International Diagnostic Interview (Kessler and Ustun, 2004) were used for the endorsement of past 12-month DSM-IV depression using the same algorithm used in previous studies using the 
same dataset (Koyanagi et al., 2014; Garin et al., 2016) (Details provided in eTable 1 ).

\subsubsection{Potential mediators}

2.2.3.1. Health status. was evaluated with 10 health-related questions pertaining to five health domains including: (a) mobility; (b) pain and discomfort; (c) cognition; (d) vision; (e) sleep and energy. Each of the five domains corresponds to those in common health related quality of life outcome measures such as the Short Form-12 (SF-12) (Ware et al., 1996), the Health Utilities Index Mark-3 (HUI) (Feeny et al., 1995) and the EUROQOL-5D (Kind, 1996). Each domain consists of two questions that assessed health function in the past 30 days. The actual questions can be found in supplementary eTable 2. Each item was scored on a five-point scale ranging from 'none' to 'extreme/cannot do'. For each separate domain, we used factor analysis with polychoric correlations to obtain a factor score which was later converted to scores ranging from 0 to 100 with higher values representing worse health function (Stubbs et al., 2016b, c, d).

2.2.3.2. Anxiety. In accordance with previous publications using a dataset with the identical question, those who claimed to have severe/extreme problems with worry or anxiety in the past 30 days were considered to have anxiety (Stubbs et al., 2017a; Vancampfort et al., 2017a).

2.2.3.3. Disability. was assessed with six questions on the level of difficulty in conducting standard basic activities of daily living (ADL) in the past 30 days (washing whole body, getting dressed, moving around inside home, eating, getting up from lying down, and using the toilet) (Katz et al., 1963). Those who answered severe or extreme/ cannot do to any of the six questions were considered to have disability (Koyanagi et al., 2015).

2.2.3.4. Physical activity. Levels of physical activity was assessed with the Global Physical Activity Questionnaire (Bull et al., 2009). The total amount (min) of moderate-to-vigorous physical activity in a typical week was calculated.

2.2.3.5. Alcohol consumption and smoking. referred to current smoking $(\mathrm{Y} / \mathrm{N})$ and alcohol use in the past 30 days $(\mathrm{Y} / \mathrm{N})$ respectively.

2.2.3.6. Body mass index (BMI). A stadiometer and a routinely calibrated electronic weighting scale were used to measure height and weight respectively. Body mass index (BMI) was calculated as weight in kilograms divided by height in meters squared, and categorized as $<18.5$ (underweight), 18.5-24.9 (normal), 25.0-29.9 (overweight), and $\geq 30$ (obese) $\mathrm{kg} / \mathrm{m}^{2}$.

2.2.3.7. Social cohesion. In accordance with a previous SAGE publication (Zamora-Macorra et al., 2017), a social cohesion index was created based on nine questions on the participant's involvement in community activities in the past 12 months (e.g., attended religious services, club, society, union etc) with answer options 'never (coded $=$ 0 )', 'once or twice per year (coded $=1$ )', 'once or twice per month (coded $=2$ )', 'once or twice per week (coded $=3$ )', and 'daily (coded $=4$ )'. The answers to these questions were summed (range 0-36) with higher scores indicating higher levels of social cohesion.

\subsubsection{Control variables}

These included sociodemographic variables such as sex, age, wealth, highest level of education achieved ( $\leq$ primary, secondary, $\geq$ tertiary), marital status (married/cohabiting or never married/separated/divorced/widowed), setting (urban or rural), and employment status (engaged in paid work $\geq 2$ days in last 7 days: $\mathrm{Y} / \mathrm{N}$ ). Wealth quintiles were created based on country-specific income. These variables were not considered as potential mediators as sociodemographic variables are generally considered to be non-modifiable.

\subsection{Statistical analysis}

The statistical analysis was done with Stata 14.1 (Stata Corp LP, College station, Texas). The difference in sample characteristics between those with and without depression or high SB was tested by Student's $t$-tests and Chi-squared tests for continuous and categorical variables, respectively. Multivariable logistic and linear regression analyses were used to assess the association between depression (exposure) and SB (outcome). The main analysis consisted of the logistic regression analysis using the binary $\mathrm{SB}$ variable (i.e., $<8$ or $\geq 8 \mathrm{~h}$ /day) as the outcome. This analysis was intended to assess the specific association between depression and high levels of SB. A secondary analysis using linear regression with the continuous variable (min/day of SB) as the outcome was also conducted to assess increasing or decreasing levels of SB associated with depression. A base model was constructed adjusting for the sociodemographic variables (i.e., sex, age, wealth, education, marital status, setting, employment status), and country.

Next, in order to gain an understanding of the extent to which various factors may explain the relation between depression and high $\mathrm{SB}$, we conducted mediation analysis. Specifically, we focused on mobility, pain and discomfort, cognition, sleep and energy, vision, anxiety, and disability, physical activity, alcohol consumption, smoking, BMI, and social cohesion for their previously reported association with the exposure (depression) and the outcome (high SB) (Stubbs et al., 2014; Biswas et al., 2015; O'Donoghue et al., 2016; Lakerveld et al., 2017; Prince et al., 2017; Wirth et al., 2017). We used the khb (Karlson Holm Breen) command in Stata (Breen et al., 2013) for this purpose. This method can be applied in logistic regression models and decomposes the total effect (i.e., unadjusted for the mediator) of a variable into direct (i.e., the effect of depression on SB adjusted for the mediator) and indirect effects (i.e., the mediational effect). Using this method, the percentage of the main association explained by the mediator can also be calculated (mediated percentage). Each potential mediator was included in the model individually. The mediation analysis controlled for the sociodemographic variables and country.

For the regression analyses, we conducted analysis using the overall sample and by age groups (age 18-49, 50-64, $\geq 65$ years). All regression analyses were adjusted for country by including dummy variables for each country. All variables were included in the models as categorical variables with the exception of the variable on age, $\mathrm{min} /$ day of SB, social cohesion, health status (mobility, pain and discomfort, cognition, sleep and energy, vision), and physical activity (continuous variables). Under $3 \%$ of the data were missing for the variables used in the current analysis with the exception of BMI (5.8\%). Complete case analysis was done. The sample weighting and the complex study design were taken into account in all analyses. Results from the regression analyses are presented as odds ratios (ORs) or b-coefficients with $95 \%$ confidence intervals (CIs). The level of statistical significance was set at $\mathrm{P}<0.05$.

\section{Results}

A total of 42,469 (China $\mathrm{n}=14,811$; Ghana $\mathrm{n}=5108$; India $\mathrm{n}=$ 11,230; Mexico $n=2742$; Russia $n=4355$; South Africa $n=4223$ ) individuals (50.1\% female) with a mean (SD) age of 43.8 (14.4) years were included in the analysis. The overall prevalence $(95 \% \mathrm{CI})$ of high SB (i.e., $\geq 8 \mathrm{~h} /$ day of SB) was $8.3 \%$ (7.1-9.7\%), while the mean (SD) minutes/day spent sedentary across the whole sample was 207 (149). The overall prevalence $(95 \% \mathrm{CI})$ of depression was $4.1 \%$ (3.6-4.6\%). The prevalence of depression was particularly high among those with $\geq 8 \mathrm{~h}$ hours/day of SB, with $9.36 \%$ of those spending $\geq 11 \mathrm{~h}$ /day sedentary having depression (see Fig. 1). The sample characteristics are provided in Table 1. Factors such as older age, not being married/cohabiting, unemployment, mobility limitations, sleep/energy disruption, 


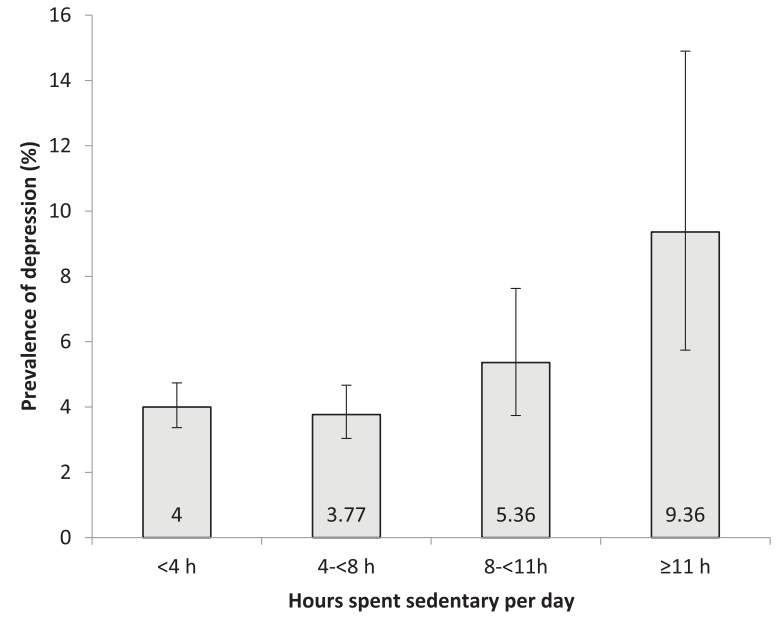

Fig. 1. Prevalence of depression by hours of sedentary behavior per day, Estimates are based on weighted sample. Bars denote $95 \%$ confidence intervals.

and disability were strongly associated with both depression and high SB.

In models adjusted for sociodemographics and country, depression was associated with a $1.94(95 \% \mathrm{CI}=1.31-2.85)$ times higher odds for
Table 2

Association between depression and sedentary behavior assessed by multivariable logistic and linear regression (overall and by age groups).

\begin{tabular}{|c|c|c|c|c|}
\hline \multirow[b]{2}{*}{ Sample } & \multicolumn{2}{|c|}{$\begin{array}{l}\text { Logistic regression } \\
\left.\text { Outcome (high } \mathrm{SB}^{\mathrm{a}}\right)\end{array}$} & \multicolumn{2}{|c|}{$\begin{array}{l}\text { Linear regression } \\
\text { Outcome (min/day of } \mathrm{SB} \text { ) }\end{array}$} \\
\hline & OR & $95 \% \mathrm{CI}$ & b-coefficient & $95 \% \mathrm{CI}$ \\
\hline Overall $^{\mathrm{b}}$ & $1.94^{k * * * *}$ & {$[1.31,2.85]$} & $25.57^{* *}$ & {$[8.46,42.69]$} \\
\hline Age $18-49$ years $^{\mathrm{b}}$ & $2.19^{*}$ & {$[1.06,4.52]$} & $26.33^{*}$ & {$[1.36,51.31]$} \\
\hline Age $50-64$ years $^{\mathrm{b}}$ & $1.66^{*}$ & {$[1.11,2.49]$} & $22.84^{*}$ & {$[0.77,44.92]$} \\
\hline Age $\geq 65$ years $^{\mathrm{b}}$ & $1.72^{\text {** }}$ & {$[1.21,2.45]$} & $35.55^{* *}$ & {$[8.59,62.52]$} \\
\hline
\end{tabular}

Abbreviation: SB Sedentary behavior; OR Odds ratio; CI Confidence interval.

a Those reporting $\geq 8 \mathrm{~h}$ per day spent sedentary were considered to be highly sedentary.

${ }^{\mathrm{b}}$ Adjusted for sex, age, wealth, education, marital status, setting, employment status, and country.

${ }^{*} \mathrm{p}<0.05$.

$* * \mathrm{p}<0.01$

$* * * \mathrm{p}<0.001$

high SB, while the mean time spent sedentary was $26(95 \% \mathrm{CI}=9-43)$ minutes longer per day among depressed individuals (Table 2). Estimates across age groups were similar. The results of the mediation analysis that assessed the degree to which the association between depression and high SB can be explained by various factors are

Table 1

Characteristics of the study sample.

\begin{tabular}{|c|c|c|c|c|c|c|c|c|c|}
\hline \multirow[b]{2}{*}{ Characteristic } & & \multirow[b]{2}{*}{ Unweighted N } & \multirow[b]{2}{*}{ Overall } & \multicolumn{2}{|l|}{ Depression } & \multirow[b]{2}{*}{ P-value ${ }^{b}$} & \multicolumn{3}{|c|}{ Highly sedentary behavior ${ }^{a}$} \\
\hline & & & & No & Yes & & No & Yes & P-value ${ }^{b}$ \\
\hline Sex & Female & 24,137 & 50.1 & 49.7 & 59.9 & $<0.001$ & 50.1 & 50.6 & 0.853 \\
\hline \multirow[t]{4}{*}{ Age (years) } & $18-49$ & 8340 & 72.7 & 73.3 & 59.5 & $<0.001$ & 73.5 & 64.7 & $<0.001$ \\
\hline & $50-64$ & 19,544 & 17.0 & 16.7 & 24.1 & & 17.1 & 15.8 & \\
\hline & $\geq 65$ & 14,585 & 10.3 & 10.0 & 16.4 & & 9.4 & 19.6 & \\
\hline & Mean (SD) & & $43.8(14.4)$ & $43.6(14.3)$ & $48.0(16.7)$ & $<0.001$ & $43.6(14.0)$ & $46.6(17.7)$ & 0.022 \\
\hline \multirow[t]{5}{*}{ Wealth } & Poorest & 7954 & 14.9 & 14.5 & 24.8 & $<0.001$ & 15.1 & 13.2 & 0.099 \\
\hline & Poorer & 8292 & 17.8 & 17.6 & 24.2 & & 18.0 & 16.3 & \\
\hline & Middle & 8259 & 18.8 & 18.7 & 20.4 & & 18.7 & 21.4 & \\
\hline & Richer & 8758 & 21.1 & 21.4 & 14.4 & & 21.7 & 15.9 & \\
\hline & Richest & 9026 & 27.3 & 27.8 & 16.2 & & 26.6 & 33.2 & \\
\hline \multirow[t]{3}{*}{ Education } & $\leq$ Primary & 25,451 & 43.1 & 42.2 & 63.1 & $<0.001$ & 44.1 & 33.2 & 0.001 \\
\hline & Secondary & 13,231 & 46.5 & 47.2 & 31.7 & & 45.9 & 51.5 & \\
\hline & $\geq$ Tertiary & 2935 & 10.4 & 10.6 & 5.2 & & 10.0 & 15.2 & \\
\hline Marital status & Married/cohabiting & 11,774 & 80.8 & 81.4 & 69.6 & $<0.001$ & 82.0 & 72.1 & $<0.001$ \\
\hline Setting & Rural & 22,182 & 55.6 & 55.4 & 64.4 & 0.016 & 57.5 & 37.0 & $<0.001$ \\
\hline Unemployed & Yes & 23,778 & 38.5 & 37.9 & 51.6 & $<0.001$ & 37.5 & 49.4 & $<0.001$ \\
\hline Physical activity $(\mathrm{min})^{\mathrm{c}}$ & Mean (SD) & & $1440(1500)$ & 1443 (1498) & 1380 (1529) & 0.464 & $1480(1517)$ & 1001 (1237) & $<0.001$ \\
\hline Alcohol consumption & Yes & 7805 & 21.9 & 22.3 & 9.7 & $<0.001$ & 21.7 & 21.2 & 0.865 \\
\hline Smoking & Yes & 11,275 & 35.2 & 35.0 & 39.2 & 0.130 & 34.9 & 36.6 & 0.617 \\
\hline \multirow[t]{4}{*}{ Body mass index $\left(\mathrm{kg} / \mathrm{m}^{2}\right)$} & Underweight & 5343 & 16.8 & 16.1 & 35.4 & $<0.001$ & 17.3 & 13.3 & 0.005 \\
\hline & Normal & 19,817 & 55.3 & 55.7 & 46.6 & & 55.7 & 53.1 & \\
\hline & Overweight & 9625 & 20.9 & 21.2 & 13.5 & & 20.5 & 22.9 & \\
\hline & Obese & 5229 & 7.0 & 7.0 & 4.6 & & 6.6 & 10.7 & \\
\hline Social cohesion $^{\mathrm{d}}$ & Mean (SD) & & $8.6(4.9)$ & $8.6(4.8)$ & $8.7(6.0)$ & 0.760 & $8.7(4.9)$ & $7.3(4.3)$ & $<0.001$ \\
\hline Mobility $^{\mathrm{e}}$ & Mean (SD) & & $18.0(23.8)$ & $16.8(22.8)$ & $46.5(29.7)$ & $<0.001$ & $17.4(23.1)$ & $25.3(29.0)$ & $<0.001$ \\
\hline Pain and discomfort ${ }^{\mathrm{e}}$ & Mean (SD) & & $19.6(24.4)$ & $18.4(23.5)$ & $47.8(27.8)$ & $<0.001$ & $19.4(24.1)$ & $23.2(26.9)$ & 0.021 \\
\hline Cognition $^{\mathrm{e}}$ & Mean (SD) & & $16.8(23.6)$ & $15.8(22.7)$ & $41.8(30.9)$ & $<0.001$ & $16.7(23.2)$ & $19.6(27.3)$ & 0.056 \\
\hline Sleep and energy & Mean (SD) & & $17.1(23.4)$ & $16.0(22.3)$ & $43.9(31.4)$ & $<0.001$ & $16.4(23.0)$ & $24.4(26.0)$ & $<0.001$ \\
\hline Vision $^{\mathrm{e}}$ & Mean (SD) & & $14.6(22.4)$ & $13.9(21.8)$ & $31.3(31.1)$ & $<0.001$ & $14.3(22.0)$ & $18.3(25.6)$ & 0.006 \\
\hline Anxiety & Yes & 2630 & 5.7 & 4.2 & 42.1 & $<0.001$ & 5.6 & 7.6 & 0.037 \\
\hline Disability & Yes & 2440 & 3.1 & 2.5 & 18.0 & $<0.001$ & 2.6 & 8.4 & $<0.001$ \\
\hline
\end{tabular}

Abbreviation: SD Standard deviation.

Data are column percentage unless otherwise stated.

Estimates are based on weighted sample apart from the unweighted $\mathrm{N}$.

a Those spending $\geq 8 \mathrm{~h}$ per day sedentary were considered to be highly sedentary.

${ }^{b}$ The difference in sample characteristics by depression and sedentary behavior was tested by Chi-squared tests and Student's $t$-tests for categorical and continuous variables respectively.

c The total amount of moderate-to-vigorous physical activity in a typical week.

d Scores ranged from 0 to 36 with higher scores representing higher levels of social cohesion.

e Scores ranged from 0 to 100 with higher scores representing worse health status. 
illustrated in Tables 3, 4. Based on the overall sample, the largest proportion of the total effect was explained by mobility limitations (49.9\%), followed by impairments in sleep/energy (43.4\%), pain/discomfort (31.1\%), anxiety (30.0\%), disability (25.6\%), cognition (16.1\%), and problems with vision (11.0\%) (Table 3). Mobility and pain/discomfort explained more than $50 \%$ of the association in individuals aged $\geq 65$ years. Cognition and anxiety were important mediators mainly among older adults. Health behaviors (physical activity, alcohol consumption, smoking), BMI, and social cohesions were not significant mediators (i.e., no significant indirect effects) in the overall sample or any of the age groups (Table 4).

\section{Discussion}

To the best of our knowledge, ours is the first multi-national study to investigate the relationship between depression and SB and its influential factors. Our data suggest that higher levels of SB (particularly over $11 \mathrm{~h}$ ) are associated with an elevated prevalence of depression. The relationship between high levels of SB and depression held across the lifespan, and depression across the entire sample was associated with a 26-min increase in SB per day. Previous research has found that such differences in SB are associated with worse cardiometabolic health (Katzmarzyk, 2010; Katzmarzyk and Lee, 2012), increased inflammation and worse mood profile (Endrighi et al., 2015). Interestingly, we found evidence that mobility limitations, disability and sleep problems explained the relationship between depression and SB across all age ranges. Moreover, smoking, alcohol consumption, BMI, physical activity and social cohesion had little influence in the association between depression and SB. Given the high levels of SB among those with depression previously reported (Schuch et al., 2016a, b), and the deleterious outcomes of high levels of SB in the general population (Biswas et al., 2015), our data provide important insights that might help shape future interventions.

In addition to extending the literature on being the first multinational study to explore the association between depression and SB, our study provides some indication of factors that may influence this relationship. Perhaps unsurprisingly, we found evidence across all age groups that mobility limitations mediated $49 \%$ of the association between SB and depression. Mobility limitations can arise from a multitude of problems, and have previously been associated with SB (Stubbs et al., 2014) and an increased risk of developing depression (Veronese et al., 2017). Importantly, increasing PA among people with mobility limitations can reduce the risk of developing activities of daily living difficulties (Tak et al., 2013) and promote healthy ageing (Daskalopoulou et al., 2017). When one considers that low PA is associated with depression (Mammen and Faulkner, 2013) and depression reduces with participation in PA (Schuch et al., 2016a, b), strategies such as sitting reduction interventions tailored to those with mobility limitations may play a pivotal role in this population. We also observed that pain, particularly among older adults explained a considerable proportion of the association between SB and depression. Pain is known to be highly comorbid with depression (Stubbs et al., 2016b, c, d, 2017b, c, d), particularly among older adults (Abdulla et al., 2013) and is associated with low PA (Stubbs et al., 2013) and SB (Stubbs et al., 2014). Interestingly, we also found a relationship between sleep and energy problems as an important influential factor across all age ranges. Sleep and energy issues are known to be a core feature of depression and are closely linked to energy expenditure (Luca et al., 2013). Prolonged periods of SB are known to increase tiredness and predispose people to "napping" which has been associated with depression (Luca et al., 2013) and other deleterious outcomes such as a poor cardiometabolic profile (Yamada et al., 2015). Future interventions that address sleep and in particular daytime napping may play an important role in preventing high levels of SB and depression.

Whilst in the overall sample, anxiety mediated $30 \%$ of the association between SB and depression, this relationship was only evident in working and older age adults. Depression and anxiety are often comorbid (Rebar et al., 2017) and anxiety has been associated with SB

Table 3

Health status, anxiety, and disability as mediators in the association between depression and highly sedentary behavior (overall and by age groups).

\begin{tabular}{|c|c|c|c|c|c|c|c|c|}
\hline Mediator & Sample & Total effect & P-value & Direct effect & P-value & Indirect effect & P-value & $\%$ Mediated \\
\hline \multirow[t]{4}{*}{ Mobility } & Overall & $1.95[1.32,2.89]$ & 0.001 & $1.40[0.94,2.09]$ & 0.100 & $1.40[1.25,1.56]$ & $<0.001$ & 49.9 \\
\hline & Age $18-49$ years & $2.20[1.06,4.57]$ & 0.034 & $1.64[0.77,3.50]$ & 0.200 & $1.34[1.08,1.67]$ & 0.008 & 37.2 \\
\hline & Age $50-64$ years & $1.65[1.09,2.48]$ & 0.017 & $1.29[0.85,1.96]$ & 0.225 & $1.27[1.17,1.38]$ & $<0.001$ & 48.2 \\
\hline & Age $\geq 65$ years & $1.77[1.23,2.55]$ & 0.002 & $1.29[0.91,1.84]$ & 0.156 & $1.37[1.23,1.53]$ & $<0.001$ & 55.2 \\
\hline \multirow[t]{4}{*}{ Pain and discomfort } & Overall & $1.93[1.32,2.83]$ & 0.001 & $1.58[1.07,2.32]$ & 0.021 & $1.23[1.12,1.34]$ & $<0.001$ & 31.1 \\
\hline & Age $18-49$ years & $2.18[1.07,4.44]$ & 0.032 & $1.88[0.91,3.86]$ & 0.087 & $1.16[0.99,1.37]$ & 0.075 & NA \\
\hline & Age $50-64$ years & $1.67[1.11,2.52]$ & 0.014 & $1.38[0.92,2.07]$ & 0.121 & $1.21[1.12,1.31]$ & $<0.001$ & 37.3 \\
\hline & Age $\geq 65$ years & $1.75[1.23,2.50]$ & 0.002 & $1.30[0.92,1.86]$ & 0.140 & $1.34[1.22,1.48]$ & $<0.001$ & 52.7 \\
\hline \multirow[t]{4}{*}{ Cognition } & Overall & $1.93[1.30,2.85]$ & 0.001 & $1.73[1.16,2.59]$ & 0.007 & $1.11[1.03,1.20]$ & 0.005 & 16.1 \\
\hline & Age $18-49$ years & $2.20[1.06,4.55]$ & 0.034 & $2.43[1.14,5.18]$ & 0.022 & $0.90[0.75,1.09]$ & 0.281 & NA \\
\hline & Age $50-64$ years & $1.67[1.11,2.52]$ & 0.014 & $1.38[0.92,2.09]$ & 0.124 & $1.21[1.12,1.30]$ & $<0.001$ & 37.0 \\
\hline & Age $\geq 65$ years & $1.75[1.21,2.53]$ & 0.003 & $1.48[1.02,2.15]$ & 0.038 & $1.18[1.10,1.26]$ & $<0.001$ & 29.7 \\
\hline \multirow[t]{4}{*}{ Sleep and energy } & Overall & $1.89[1.27,2.82]$ & 0.002 & $1.43[0.95,2.17]$ & 0.088 & $1.32[1.17,1.48]$ & $<0.001$ & 43.4 \\
\hline & Age $18-49$ years & $2.11[0.99,4.49]$ & 0.053 & $1.53[0.70,3.34]$ & 0.284 & $1.38[1.13,1.68]$ & 0.002 & 42.8 \\
\hline & Age $50-64$ years & $1.66[1.10,2.51]$ & 0.015 & $1.35[0.89,2.04]$ & 0.154 & $1.23[1.12,1.35]$ & $<0.001$ & 40.9 \\
\hline & Age $\geq 65$ years & $1.75[1.22,2.50]$ & 0.002 & $1.47[1.02,2.13]$ & 0.039 & $1.19[1.10,1.28]$ & $<0.001$ & 30.5 \\
\hline \multirow[t]{4}{*}{ Vision } & Overall & $1.91[1.29,2.82]$ & 0.001 & $1.78[1.21,2.62]$ & 0.004 & $1.07[1.02,1.13]$ & 0.003 & 11.0 \\
\hline & Age $18-49$ years & $2.14[1.04,4.41]$ & 0.039 & $2.02[0.99,4.16]$ & 0.055 & $1.06[0.97,1.15]$ & 0.180 & NA \\
\hline & Age $50-64$ years & $1.68[1.12,2.52]$ & 0.012 & $1.60[1.07,2.39]$ & 0.023 & $1.05[1.00,1.11]$ & 0.033 & 10.0 \\
\hline & Age $\geq 65$ years & $1.73[1.21,2.49]$ & 0.003 & $1.62[1.13,2.30]$ & 0.008 & $1.07[1.02,1.13]$ & 0.005 & 12.9 \\
\hline \multirow[t]{4}{*}{ Anxiety } & Overall & $1.89[1.26,2.83]$ & 0.002 & $1.56[1.01,2.42]$ & 0.047 & $1.21[1.08,1.35]$ & $<0.001$ & 30.0 \\
\hline & Age $18-49$ years & $2.17[1.03,4.56]$ & 0.042 & $1.95[0.86,4.43]$ & 0.109 & $1.11[0.90,1.38]$ & 0.341 & NA \\
\hline & Age $50-64$ years & $1.63[1.08,2.45]$ & 0.019 & $1.31[0.86,1.97]$ & 0.205 & $1.25[1.11,1.41]$ & $<0.001$ & 45.4 \\
\hline & Age $\geq 65$ years & $1.71[1.19,2.44]$ & 0.004 & $1.42[0.97,2.06]$ & 0.068 & $1.20[1.08,1.34]$ & $<0.001$ & 34.9 \\
\hline \multirow[t]{4}{*}{ Disability } & Overall & $1.85[1.23,2.78]$ & 0.003 & $1.58[1.04,2.39]$ & 0.031 & $1.17[1.10,1.25]$ & $<0.001$ & 25.6 \\
\hline & Age $18-49$ years & $2.12[0.99,4.50]$ & 0.052 & $1.81[0.83,3.94]$ & 0.133 & $1.17[1.04,1.31]$ & 0.011 & 20.5 \\
\hline & Age $50-64$ years & $1.64[1.09,2.47]$ & 0.018 & $1.53[1.00,2.32]$ & 0.048 & $1.07[1.02,1.13]$ & 0.007 & 14.5 \\
\hline & Age $\geq 65$ years & $1.68[1.14,2.45]$ & 0.008 & $1.37[0.94,2.00]$ & 0.097 & $1.22[1.12,1.32]$ & $<0.001$ & 38.4 \\
\hline
\end{tabular}

Data are odds ratio [95\% confidence interval].

Models are adjusted for sex, age, wealth, education, marital status, setting, employment status, and country.

The mediated percentage was calculated only when the indirect effect was significant $(\mathrm{P}<0.05)$. 
Table 4

Physical activity, alcohol consumption, smoking, body mass index, and social cohesion as mediators in the association between depression and highly sedentary behavior.

\begin{tabular}{|c|c|c|c|c|c|c|c|}
\hline Mediator & Sample & Total effect & P-value & Direct effect & P-value & Indirect effect & P-value \\
\hline \multirow[t]{4}{*}{ Physical activity } & Overall & $1.98[1.33,2.95]$ & 0.001 & $1.93[1.30,2.87]$ & 0.001 & $1.03[0.99,1.07]$ & 0.649 \\
\hline & Age $18-49$ years & $2.23[1.07,4.68]$ & 0.033 & $2.20[1.05,4.59]$ & 0.036 & $1.02[0.97,1.07]$ & 0.512 \\
\hline & Age 50-64 years & $1.66[1.10,2.51]$ & 0.016 & $1.63[1.08,2.47]$ & 0.020 & $1.02[0.98,1.05]$ & 0.311 \\
\hline & Age $\geq 65$ years & $1.77[1.22,2.55]$ & 0.003 & $1.71[1.17,2.50]$ & 0.006 & $1.04[0.98,1.10]$ & 0.212 \\
\hline \multirow[t]{4}{*}{ Alcohol consumption } & Overall & $1.94[1.32,2.86]$ & 0.001 & $1.94[1.31,2.85]$ & 0.001 & $1.00[0.99,1.01]$ & 0.734 \\
\hline & Age $18-49$ years & $2.20[1.08,4.50]$ & 0.030 & $2.18[1.07,4.43]$ & 0.031 & $1.01[0.98,1.04]$ & 0.448 \\
\hline & Age 50-64 years & $1.66[1.10,2.50]$ & 0.015 & $1.66[1.10,2.50]$ & 0.016 & $1.00[0.99,1.01]$ & 0.550 \\
\hline & Age $\geq 65$ years & $1.72[1.20,2.46]$ & 0.003 & $1.72[1.20,2.46]$ & 0.003 & $1.00[0.99,1.01]$ & 0.932 \\
\hline \multirow[t]{4}{*}{ Smoking } & Overall & $1.93[1.31,2.84]$ & 0.001 & $1.91[1.30,2.81]$ & 0.001 & $1.01[0.99,1.03]$ & 0.276 \\
\hline & Age $18-49$ years & $2.18[1.06,4.46]$ & 0.033 & $2.18[1.07,4.47]$ & 0.033 & $1.00[0.97,1.03]$ & 0.910 \\
\hline & Age $50-64$ years & $1.66[1.11,2.50]$ & 0.015 & $1.66[1.10,2.49]$ & 0.015 & $1.00[0.99,1.01]$ & 0.491 \\
\hline & Age $\geq 65$ years & $1.73[1.21,2.47]$ & 0.003 & $1.71[1.19,2.45]$ & 0.003 & $1.01[0.99,1.03]$ & 0.201 \\
\hline \multirow[t]{4}{*}{ Body mass index $\left(\mathrm{kg} / \mathrm{m}^{2}\right)$} & Overall & $1.97[1.31,2.96]$ & 0.001 & $1.97[1.31,2.96]$ & 0.001 & $1.00[0.99,1.02]$ & 0.901 \\
\hline & Age $18-49$ years & $2.23[1.09,4.58]$ & 0.028 & $2.26[1.10,4.64]$ & 0.026 & $0.99[0.96,1.02]$ & 0.472 \\
\hline & Age 50-64 years & $1.63[1.05,2.54]$ & 0.031 & $1.61[1.03,2.54]$ & 0.037 & $1.01[0.98,1.04]$ & 0.494 \\
\hline & Age $\geq 65$ years & $1.76[1.19,2.59]$ & 0.004 & $1.78[1.21,2.62]$ & 0.004 & $0.99[0.97,1.01]$ & 0.328 \\
\hline \multirow[t]{4}{*}{ Social cohesion } & Overall & $1.92[1.30,2.83]$ & 0.001 & $1.91[1.29,2.82]$ & 0.001 & $1.00[0.98,1.03]$ & 0.782 \\
\hline & Age $18-49$ years & $2.17[1.05,4.48]$ & 0.037 & $2.17[1.05,4.48]$ & 0.037 & $1.00[0.98,1.02]$ & 0.997 \\
\hline & Age $50-64$ years & $1.65[1.09,2.50]$ & 0.018 & $1.63[1.08,2.46]$ & 0.021 & $1.01[0.98,1.04]$ & 0.361 \\
\hline & Age $\geq 65$ years & $1.73[1.22,2.45]$ & 0.002 & $1.70[1.20,2.41]$ & 0.003 & $1.02[0.98,1.06]$ & 0.315 \\
\hline
\end{tabular}

Data are odds ratio [95\% confidence interval].

Models are adjusted for sex, age, wealth, education, marital status, setting, employment status, and country.

The mediated percentage was not calculated as the indirect effect was not significant for any of the mediators.

(Teychenne et al., 2015). Whilst PA can reduce anxiety symptoms (Stubbs et al., 2017b, c, d), our data suggest that PA does not per se influence the SB and depression relationship. Whilst our data cannot provide a causal inference, some previous studies can provide some indication of a potentially causal relationship which underpin our assertions. For instance, previous research from randomized controlled trials in Western samples has demonstrated the independent deleterious impact of increasing SB on mood and in particular symptoms of anxiety (Edwards and Loprinzi, 2016), possibly through changes in inflammation (Endrighi et al., 2015). Previous research has also suggested that SB is associated with inflammation, most notably c-reactive protein and interleukin 6 (Henson et al., 2013; Wirth et al., 2017). There is some provisional evidence to suggest that standing and breaking up prolonged periods of SB can improve inflammatory biomarker profiles (Healy et al., 2008, 2011; Owen et al., 2010; Hansen et al., 2012). Thus, future interventions may consider investigating the potential benefits of disrupting SB on mood (depression and anxiety) and underlying mechanisms of potential change, such as inflammation. We also found some evidence that cognition influenced SB and depression, notably among working and older age adults. There is evidence that both depression (Rock et al., 2014) and SB (Falck et al., 2016) are associated with cognitive impairment. Whether or not reducing SB can improve cognition is unclear, although there is robust evidence that PA can improve cognition (Stanmore et al., 2017), however, this did not appear to influence the SB and depression relationship in our data.

Surprisingly, none of the measured health behaviors (alcohol use, PA, smoking), or risk factors (body mass index, social cohesion) influenced the SB-depression relationship. Many of these findings are inconsistent with the wider literature. For example, PA has been shown to have a multitude of benefits for both depression and many of the other potential influencing factors (e.g. disability, mobility, cognition), and so could be expected to influence the impact of SB on depression. Similarly, BMI is known to be associated with SB (Wirth et al., 2017) and depression (Vancampfort et al., 2015, 2016; Fornaro et al., 2017). However, simply being correlated with both SB and depression does not mean that BMI is a potential mediator of this relationship and clearly, future longitudinal research is required to disentangle the relationships we observed and explore potentially modifiable mediators. Future research is also required to consider the type and context of SB (e.g. sitting at home, work) and depression, preferably using a longitudinal design and objective measures of SB.
The current findings should be interpreted in light of some limitations. First, the study is cross-sectional, therefore the directionality of the relationships cannot be deduced with certainty. The aim of the study was only to quantify the degree to which potentially influential factors in the depression-SB relationship may explain this association. Thus, directionality or causality cannot be established and the effect of these influential factors as mediators or confounders cannot be known. Therefore, future longitudinal studies are required to better disentangle the relationships we observed. Second, SB was captured with a selfreport measure, the accuracy of which has been questioned (Soundy et al., 2014; Stubbs et al., 2016a). Future research should utilize objective measures of SB. Accelerometers-inclinometers are available that allow for valid and reliable objective measures of SB (Grant et al., 2006). Finally, we have not investigated context specific SB (e.g. TV viewing) which may provide important insights into the underlying relationships we observed. Nonetheless, the strengths of the study include the large sample size (over 42,000) and the multi-national scope. Most of the research in the domain of SB and depression has been conducted in Western countries, and little is known about these experiences and mediators in regions across which there are multiple economic, cultural or social factors or differences in the health systems. The present study was furthermore performed with nationally representative samples of non-institutionalized persons. Moreover, by conducting mediation analyses, we have advanced the understanding of factors influencing SB and depression, which has largely been missing from the literature to date.

In conclusion, our paper provides evidence of a relationship between SB and depression. In fact, across this representative cohort over 6 countries, being depressed was associated with 26 more daily minutes of sedentary time. Mobility limitations, pain and discomfort, cognition problems, sleep and energy issues, anxiety and disability may potentially influence the relationship between SB and depression. If replicated using longitudinal designs to more reliably establish directionality/causality, these findings could offer important new targets and strategies for interventions to tackle the depression-SB relationship.

\section{Funding}

AK's work was supported by the Miguel Servet contract financed by the CP13/00150 and PI15/00862 projects, integrated into the National $\mathrm{R}+\mathrm{D}+\mathrm{I}$ and funded by the ISCIII - General Branch Evaluation and 
Promotion of Health Research - and the European Regional Development Fund (ERDF-FEDER). BS receives funding from the National Institute for Health Research Collaboration for Leadership in Applied Health Research \& Care Funding scheme. BS is part funded by the National Institute for Health Research (NIHR) Biomedical Research Centre at South London and Maudsley NHS Foundation Trust and King's College London.The views expressed in this publication are those of the author(s) and not necessarily those of the NHS, the National Institute for Health Research or the Department of Health.

\section{Appendix A. Supplementary material}

Supplementary data associated with this article can be found in the online version at http://dx.doi.org/10.1016/j.jad.2017.12.104.

\section{References}

Abdulla, A., Bone, M., Adams, N., Elliott, A.M., Jones, D., Knaggs, R., Martin, D., Sampson, E.L., Schofield, P., 2013. Evidence-based clinical practice guidelines on management of pain in older people. Age Ageing 42, 151-153.

Adamson, B.C., Yang, Y., Motl, R.W., 2016. Association between compliance with physical activity guidelines, sedentary behavior and depressive symptoms. Prev. Med. 91, 152-157.

Atkinson, K., Lowe, S., Moore, S., 2016. Human development, occupational structure and physical inactivity among 47 low and middle income countries. Prev. Med. Rep. 3, $40-45$.

Bennie, J.A., Chau, J.Y., van der Ploeg, H.P., Stamatakis, E., Do, A., Bauman, A., 2013. The prevalence and correlates of sitting in European adults - a comparison of 32 Eurobarometer-participating countries. Int. J. Behav. Nutr. Phys. Act. 10, 107.

Biswas, A., Oh, P.I., Faulkner, G.E., Bajaj, R.R., Silver, M.A., Mitchell, M.S., Alter, D.A., 2015. Sedentary time and its association with risk for disease incidence, mortality, and hospitalization in adults: a systematic review and meta-analysis. Ann. Intern. Med. 162 (2), 123-132.

Breen, R., Karlson, K.B., Holm, A., 2013. Total, direct, and indirect effects in logit and probit models. Sociol. Methods Res. 42 (2), 164-191.

Bull, F.C., Maslin, T.S., Armstrong, T., 2009. Global physical activity questionnaire (GPAQ): nine country reliability and validity study. J. Phys. Act. Health 6 (6), 790-804.

Christensen, K., Doblhammer, G., Rau, R., Vaupel, J.W., 2009. Ageing populations: the challenges ahead. Lancet 374 (9696), 1196-1208.

Correll, C.U., Solmi, M., Veronese, N., Bortolato, B., Rosson, S., Santonastaso, P., ThapaChhetri, N., Fornaro, M., Gallicchio, D., Collantoni, E., Pigato, G., Favaro, A., Monaco, F., Kohler, C., Vancampfort, D., Ward, P.B., Gaughran, F., Carvalho, A.F., Stubbs, B., 2017. Prevalence, incidence and mortality from cardiovascular disease in patients with pooled and specific severe mental illness: a large-scale meta-analysis of 3,211,768 patients and 113,383,368 controls. World Psychiatry 16 (2), 163-180.

Daskalopoulou, C., Stubbs, B., Kralj, C., Koukounari, A., Prince, M., Prina, A.M., 2017. Physical activity and healthy ageing: a systematic review and meta-analysis of longitudinal cohort studies. Ageing Res Rev.

Edwards, M.K., Loprinzi, P.D., 2016. Experimentally increasing sedentary behavior results in increased anxiety in an active young adult population. J. Affect. Disord. 204, 166-173.

Ekelund, U., Steene-Johannessen, J., Brown, W.J., Fagerland, M.W., Owen, N., Powell, K.E., Bauman, A., Lee, I.-M., Series, L.P.A., Group, L.S.B.W., 2016a. Does physical activity attenuate, or even eliminate, the detrimental association of sitting time with mortality? A harmonised meta-analysis of data from more than 1 million men and women. Lancet 388 (10051), 1302-1310.

Ekelund, U., Steene-Johannessen, J., Brown, W.J., Fagerland, M.W., Owen, N., Powell, K.E., Bauman, A., Lee, I.M., 2016b. Does physical activity attenuate, or even eliminate, the detrimental association of sitting time with mortality? A harmonised metaanalysis of data from more than 1 million men and women. Lancet 388 (10051), $1302-1310$.

Endrighi, R., Steptoe, A., Hamer, M., 2015. The effect of experimentally induced sedentariness on mood and psychobiological responses to mental stress. Br. J. Psychiatry.: J. Ment. Sci.

Falck, R.S., Davis, J.C., Liu-Ambrose, T., 2016. What is the association between sedentary behaviour and cognitive function? A systematic review. Br. J. Sports Med.

Feeny, D., Furlong, W., Boyle, M., Torrance, G.W., 1995. Multi-attribute health status classification systems. Health Utilities Index. Pharmacoeconomics 7 (6), 490-502.

Fornaro, M., Solmi, M., Veronese, N., De Berardis, D., Buonaguro, E.F., Tomasetti, C., Perna, G., Preti, A., Carta, M.G., 2017. The burden of mood-disorder/cerebrovascular disease comorbidity: essential neurobiology, psychopharmacology, and physical activity interventions. Int. Rev. Psychiatry 29 (5), 425-435.

Garin, N., Koyanagi, A., Chatterji, S., Tyrovolas, S., Olaya, B., Leonardi, M., Lara, E., Koskinen, S., Tobiasz-Adamczyk, B., Ayuso-Mateos, J.L., Haro, J.M., 2016. Global multimorbidity patterns: a cross-sectional, population-based, multi-country study. J. Gerontol. A Biol. Sci. Med. Sci. 71 (2), 205-214.

Guerra, M., Prina, A.M., Ferri, C.P., Acosta, D., Gallardo, S., Huang, Y., Jacob, K.S., Jimenez-Velazquez, I.Z., Llibre Rodriguez, J.J., Liu, Z., Salas, A., Sosa, A.L., Williams, J.D., Uwakwe, R., Prince, M., 2016. A comparative cross-cultural study of the prevalence of late life depression in low and middle income countries. J. Affect. Disord. 190, 362-368.

Hansen, A.L.S., Wijndaele, K., Owen, N., Magliano, D.J., Thorp, A.A., Shaw, J.E., Dunstan, D.W., 2012. Adverse associations of increases in television viewing time with 5-year changes in glucose homoeostasis markers: the AusDiab study. Diabet. Med. 29 (7), 918-925.

Hawton, K., Casanas, I.C.C., Haw, C., Saunders, K., 2013. Risk factors for suicide in individuals with depression: a systematic review. J. Affect. Disord. 147 (1-3), 17-28.

Healy, G.N., Dunstan, D.W., Salmon, J., Cerin, E., Shaw, J.E., Zimmet, P.Z., Owen, N., 2008. Breaks in sedentary time. Diabetes Care 31 (4), 661-666.

Healy, G.N., Matthews, C.E., Dunstan, D.W., Winkler, E.A.H., Owen, N., 2011. Sedentary time and cardio-metabolic biomarkers in US adults: nhanes 2003-06. Eur. Heart J. 32 (5), 590-597.

Henson, J., Yates, T., Edwardson, C.L., Khunti, K., Talbot, D., Gray, L.J., Leigh, T.M., Carter, P., Davies, M.J., 2013. Sedentary time and markers of chronic low-grade inflammation in a high risk population. PLoS One 8 (10), 1-6.

Katz, S., Ford, A.B., Moskowitz, R.W., Jackson, B.A., Jaffe, M.W., 1963. Studies of illness in the aged. The index of ADL: a standardized measure of biological and psychosocial function. JAMA 185, 914-919.

Katzmarzyk, P.T., 2010. Physical activity, sedentary behavior, and health: paradigm paralysis or paradigm shift? Diabetes 59 (11), 2717-2725.

Katzmarzyk, P.T., Lee, I.M., 2012. Sedentary behaviour and life expectancy in the USA: a cause-deleted life table analysis. BMJ Open 2 (4).

Kessler, R.C., Ustun, T.B., 2004. The World Mental Health (WMH) survey initiative version of the World Health Organization (WHO) Composite International Diagnostic Interview (CIDI). Int. J. Methods Psychiatr. Res. 13 (2), 93-121.

Kind, P., 1996. The Euroqol Instrument: an Index of Health-related Quality of Life. Quality of Life and Pharmacoeconomics in Clinical Trial. Lippincott-Raven Publishers, pp. 191-201 (B. Spiker).

Kowal, P., Chatterji, S., Naidoo, N., Biritwum, R., Fan, W., Lopez Ridaura, R., Maximova, T., Arokiasamy, P., Phaswana-Mafuya, N., Williams, S., Snodgrass, J.J., Minicuci, N., D'Este, C., Peltzer, K., Boerma, J.T., 2012. Data resource profile: the World Health Organization Study on global AGEing and adult health. Int. J. Epidemiol. 41 (6), 1639-1649.

Koyanagi, A., Garin, N., Olaya, B., Ayuso-Mateos, J.L., Chatterji, S., Leonardi, M., Koskinen, S., Tobiasz-Adamczyk, B., Haro, J.M., 2014. Chronic conditions and sleep problems among adults aged 50 years or over in nine countries: a multi-country study. PLoS One 9 (12), e114742.

Koyanagi, A., Moneta, M.V., Garin, N., Olaya, B., Ayuso-Mateos, J.L., Chatterji, S. Leonardi, M., Sainio, P., Galas, A., Haro, J.M., 2015. The association between obesity and severe disability among adults aged 50 or over in nine high-income, middleincome and low-income countries: a cross-sectional study. BMJ Open 5 (4), e007313.

Lakerveld, J., Loyen, A., Schotman, N., Peeters, C.F.W., Cardon, G., van der Ploeg, H.P., Lien, N., Chastin, S., Brug, J., 2017. Sitting too much: a hierarchy of socio-demographic correlates. Prev. Med. 101, 77-83.

Loyen, A., Verloigne, M., Van Hecke, L., Hendriksen, I., Lakerveld, J., SteeneJohannessen, J., Koster, A., Donnelly, A., Ekelund, U., Deforche, B., De Bourdeaudhuij, I., Brug, J., van der Ploeg, H.P., 2016. Variation in population levels of sedentary time in European adults according to cross-European studies: a systematic literature review within DEDIPAC. Int. J. Behav. Nutr. Phys. Act. 13, 71.

Luca, A., Luca, M., Calandra, C., 2013. Sleep disorders and depression: brief review of the literature, case report, and nonpharmacologic interventions for depression. Clin. Interv. Aging 8, 1033-1039.

Mammen, G., Faulkner, G., 2013. Physical activity and the prevention of depression: a systematic review of prospective studies. Am. J. Prev. Med. 45 (5), 649-657.

Mitchell, A.J., Yadegarfar, M., Gill, J., Stubbs, B., 2016. Case finding and screening clinical utility of the Patient Health Questionnaire (PHQ-9 and PHQ-2) for depression in primary care: a diagnostic meta-analysis of 40 studies. Br. J. Psychiatry Open 2 (2), $127-138$.

Naci, H., Ioannidis, J.P.A., 2013. Comparative effectiveness of exercise and drug interventions on mortality outcomes: metaepidemiological study. BMJ (Clin. Res. Ed.) 347 (f5577-f5577).

O'Donoghue, G., Perchoux, C., Mensah, K., Lakerveld, J., van der Ploeg, H., Bernaards, C., Chastin, S.F., Simon, C., O'Gorman, D., Nazare, J.A., 2016. A systematic review of correlates of sedentary behaviour in adults aged 18-65 years: a socio-ecological approach. BMC Public Health 16, 163.

Owen, N., Healy, G.N., Matthews, C.E., Dunstan, D.W., 2010. Too much sitting: the population health science of sedentary behavior. Exerc. Sport Sci. Rev. 38 (3), 105-113.

Pengpid, S., Peltzer, K., Kassean, H.K., Tsala Tsala, J.P., Sychareun, V., MullerRiemenschneider, F., 2015. Physical inactivity and associated factors among university students in 23 low-, middle- and high-income countries. Int. J. Public Health 60 (5), 539-549.

Prince, S.A., Reed, J.L., McFetridge, C., Tremblay, M.S., Reid, R.D., 2017. Correlates of sedentary behaviour in adults: a systematic review. Obes. Rev. 18 (8), 915-935.

Rebar, A.L., Stanton, R., Rosenbaum, S., 2017. Comorbidity of depression and anxiety in exercise research. Lancet Psychiatry 4 (7), 519.

Rock, P.L., Roiser, J.P., Riedel, W.J., Blackwell, A.D., 2014. Cognitive impairment in depression: a systematic review and meta-analysis. Psychol. Med. 44 (10), 2029-2040.

Sallis, J.F., Bull, F., Guthold, R., Heath, G.W., Inoue, S., Kelly, P., Oyeyemi, A.L., Perez, L.G., Richards, J., Hallal, P.C., 2016. Progress in physical activity over the Olympic quadrennium. Lancet.

Schuch, F., Vancampfort, D., Firth, J., Rosenbaum, S., Ward, P., Reichert, T., Bagatini, N.C., Bgeginski, R., Stubbs, B., 2016a. Physical activity and sedentary behavior in people with major depressive disorder: a systematic review and meta-analysis. J. Affect. Disord. 210, 139-150. 
Schuch, F.B., Vancampfort, D., Richards, J., Rosenbaum, S., Ward, P.B., Stubbs, B., 2016b. Exercise as a treatment for depression: a meta-analysis adjusting for publication bias. J. Psychiatr. Res. 77, 42-51.

Sedentary Behaviour Research, N., 2012. Letter to the Editor: Standardized use of the terms 'sedentary' and 'sedentary behaviours'. Appl. Physiol. Nutr. Metab. 37 (3), 540-542.

Soundy, A., Roskell, C., Stubbs, B., Vancampfort, D., 2014. Selection, use and psychometric properties of physical activity measures to assess individuals with severe mental illness: a narrative synthesis. Arch. Psychiatr. Nurs. 28 (2), 135-151.

Stanmore, E., Stubbs, B., Vancampfort, D., de Bruin, E.D., Firth, J., 2017. The effect of active video games on cognitive functioning in clinical and non-clinical populations: a meta-analysis of randomized controlled trials. Neurosci. Biobehav. Rev. 78, 34-43.

Stubbs, B., Binnekade, T.T., Soundy, A., Schofield, P., Huijnen, I.P.J., Eggermont, L.H.P., 2013. Are older adults with chronic musculoskeletal pain less active than older adults Without pain? A systematic review and meta-analysis. Pain Med. 14 (9), 1316-1331.

Stubbs, B., Firth, J., Berry, A., Schuch, F. B., Rosenbaum, S., Gaughran, F., Veronesse, N., Williams, J., Craig, T., Yung, A.R., Vancampfort, D., 2016a. How much physical activity do people with schizophrenia engage in? A systematic review, comparative meta-analysis and meta-regression. Schizophr. Res.

Stubbs, B., Koyanagi, A., Schuch, F., Firth, J., Rosenbaum, S., Gaughran, F., Mugisha, J., Vancampfort, D., 2016b. physical activity levels and psychosis: a Mediation analysis of factors influencing physical activity target achievement Among 204186 people across 46 low- and Middle-income countries. Schizophr. Bull.

Stubbs, B., Koyanagi, A., Schuch, F.B., Firth, J., Rosenbaum, S., Veronese, N., Solmi, M., Mugisha, J., Vancampfort, D., 2016c. Physical activity and depression: a large crosssectional, population-based study across 36 low- and middle-income countries. Acta Psychiatr. Scand. 134 (6), 546-556.

Stubbs, B., Koyanagi, A., Thompson, T., Veronese, N., Carvalho, A.F., Solomi, M., Mugisha, J., Schofield, P., Cosco, T., Wilson, N., Vancampfort, D., 2016d. The epidemiology of back pain and its relationship with depression, psychosis, anxiety, sleep disturbances, and stress sensitivity: data from 43 low- and middle-income countries. Gen. Hosp. Psychiatry 43, 63-70.

Stubbs, B., Patchay, S., Soundy, A., Schofield, P., 2014. The avoidance of activities due to fear of falling contributes to sedentary behavior among community-dwelling older adults with chronic musculoskeletal pain: a multisite observational study. Pain Med. (Malden, Mass.).

Stubbs, B., Koyanagi, A., Hallgren, M., Firth, J., Richards, J., Schuch, F., Rosenbaum, S., Mugisha, J., Veronese, N., Lahti, J., Vancampfort, D., 2017a. Physical activity and anxiety: a perspective from the World Health Survey. J. Affect. Disord. 208, 545-552.

Stubbs, B., Vancampfort, D., Rosenbaum, S., Firth, J., Cosco, T., Veronese, N., Salum, G.A., Schuch, F.B., 2017b. An examination of the anxiolytic effects of exercise for people with anxiety and stress-related disorders: a meta-analysis. Psychiatry Res. 249, 102-108.

Stubbs, B., Vancampfort, D., Veronese, N., Kahl, K.G., Mitchell, A.J., Lin, P.Y., Tseng, P.T., Mugisha, J., Solmi, M., Carvalho, A.F., Koyanagi, A., 2017c. Depression and physical health multimorbidity: primary data and country-wide meta-analysis of population data from 190593 people across 43 low- and middle-income countries. Psychol. Med. $1-11$.

Stubbs, B., Vancampfort, D., Veronese, N., Thompson, T., Fornaro, M., Schofield, P., Solmi, M., Mugisha, J., Carvalho, A.F., Koyanagi, A., 2017d. Depression and pain: primary data and meta-analysis among 237952 people across 47 low- and middle- income countries. Psychol. Med 1-12.

Tak, E., Kuiper, R., Chorus, A., Hopman-Rock, M., 2013. Prevention of onset and progression of basic ADL disability by physical activity in community dwelling older adults: a meta-analysis. Ageing Res. Rev. 12 (1), 329-338.

Teychenne, M., Costigan, S.A., Parker, K., 2015. The association between sedentary behaviour and risk of anxiety: a systematic review. BMC Public Health 15, 513.

Tremblay, M.S., Aubert, S., Barnes, J.D., Saunders, T.J., Carson, V., Latimer-Cheung, A.E., Chastin, S.F.M., Altenburg, T.M., Chinapaw, M.J.M., 2017. Sedentary Behavior Research Network (SBRN) - Terminology Consensus Project process and outcome. Int. J. Behav. Nutr. Phys. Act. 14 (1), 75.

Vancampfort, D., Correll, C.U., Galling, B., Probst, M., De Hert, M., Ward, P.B., Rosenbaum, S., Gaughran, F., Lally, J., Stubbs, B., 2016. Diabetes mellitus in people with schizophrenia, bipolar disorder and major depressive disorder: a systematic review and large scale meta-analysis. World Psychiatry 15 (2), 166-174.

Vancampfort, D., Koyanagi, A., Hallgren, M., Probst, M., Stubbs, B., 2017a. The relationship between chronic physical conditions, multimorbidity and anxiety in the general population: a global perspective across 42 countries. General. Hosp. Psychiatry 45, 1-6.

Vancampfort, D., Stubbs, B., Herring, M.P., Hallgren, M., Koyanagi, A., 2017b. Sedentary behavior and anxiety: association and influential factors among 42,469 communitydwelling adults in six low- and middle-income countries. Gen. Hosp. Psychiatry 50, 26-32.

Vancampfort, D., Stubbs, B., Mitchell, A.J., De Hert, M., Wampers, M., Ward, P.B., Rosenbaum, S., Correll, C.U., 2015. Risk of metabolic syndrome and its components in people with schizophrenia and related psychotic disorders, bipolar disorder and major depressive disorder: a systematic review and meta-analysis. World Psychiatry.: Off. J. World Psychiatr. Assoc. (WPA) 14 (3), 339-347.

Veronese, N., Stubbs, B., Trevisan, C., Bolzetta, F., De Rui, M., Solmi, M., Sarton, L., Musacchio, E., Zambon, S., Perissinotto, E., Baggio, G., Crepaldi, G., Manzato, E., Maggi, S., Sergi, G., 2017. Poor physical performance predicts future onset of depression in elderly people: pro.V.A. longitudinal study. Phys. Ther.

Ware Jr., J., Kosinski, M., Keller, S.D., 1996. A 12-item short-form health survey: construction of scales and preliminary tests of reliability and validity. Med. Care 34 (3), 220-233.

Whiteford, H.A., Ferrari, A.J., Degenhardt, L., Feigin, V., Vos, T., 2015. The global burden of mental, neurological and substance use disorders: an analysis from the Global Burden of disease study 2010. PLoS One 10 (2), e0116820.

Wirth, K., Klenk, J., Brefka, S., Dallmeier, D., Faehling, K., Roque, I.F.M., Tully, M.A., Gine-Garriga, M., Caserotti, P., Salva, A., Rothenbacher, D., Denkinger, M., Stubbs, B., 2017. Biomarkers associated with sedentary behaviour in older adults: a systematic review. Ageing Res. Rev. 35, 87-111.

Yamada, T., Hara, K., Shojima, N., Yamauchi, T., Kadowaki, T., 2015. Daytime napping and the risk of cardiovascular disease and all-cause mortality: a prospective study and dose-response meta-analysis. Sleep 38 (12), 1945-1953.

Zamora-Macorra, M., de Castro, E.F., Avila-Funes, J.A., Manrique-Espinoza, B.S., LopezRidaura, R., Sosa-Ortiz, A.L., Shields, P.L., Del Campo, D.S., 2017. The association between social support and cognitive function in Mexican adults aged 50 and older. Arch. Gerontol. Geriatr. 68, 113-118.

Zhai, L., Zhang, Y., Zhang, D., 2015. Sedentary behaviour and the risk of depression: a meta-analysis. Br. J. Sports Med. 49 (11), 705-709. 